\title{
Text Painting, or Coincidence? Treatment of Height-Related Imagery in the Madrigals of Luca Marenzio
}

\author{
DEREK R. STRYKOWSKI[1] \\ University at Buffalo
}

\begin{abstract}
Text painting is a defining characteristic of the sixteenth-century madrigal style, especially in association with references to height. Whereas composers cannot have given musical illustration to every such reference contained within the text of a madrigal, the question of whether or not the music that accompanies a particular reference to height constitutes an actual example of text painting is sometimes unclear. To explore this problem empirically, the frequency with which musical excerpts from a corpus of 201 madrigals composed by the Italian composer Luca Marenzio satisfied three proposed definitions of height-related text painting was measured. The three definitions required a vocal part to contain either a large leap, stepwise motion, or an extreme of pitch. Positive correlations were observed between the appearance of music conforming to each of the respective definitions and the presence of height-related imagery in the text, yet only in passages that satisfied more than one definition. The research suggests that no single definition is a reliable indicator of height-related text painting, and that most legitimate examples rely on multiple compositional devices.
\end{abstract}

Submitted 2015 July 24; accepted 15 November 2015.

KEYWORDS: text painting, madrigal, Marenzio, corpus, word painting

AMONG the most recognizable characteristics of the sixteenth-century Italian madrigal style is that of text painting: the compositional device by which a musical gesture would seem to give sonic representation to the meaning of the sung word or phrase that it accompanies. The first phrase of a four-part Italian madrigal composed by Giaches de Wert and published in English translation by Nicholas Yonge in 1588, of which the cantus voice part is shown in Figure 1, provides a straightforward example of text painting.

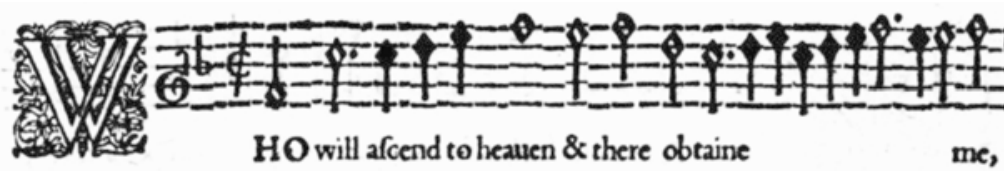

Fig. 1. The first phrase of Wert's "Who will ascend to heaven" employs text painting to depict musically the concept of heavenly ascension. From Wert (1588), cantus book, no. 11.

In this example, Wert instructs the singer to depict the meaning of the words - to "ascend to heaven"musically through both rising pitch and, in consequence, a relatively high vocal register. The singer's line ascends a full octave above its starting pitch, first by the leap of a perfect fifth and then by stepwise motion. This ascent concludes only when the singer has reached an F5, which in fact represents the upper extremity of the cantus pitch range throughout the piece. The music of the remaining three voice parts (altus, tenor, and bassus) enters in imitation of the cantus, thereby allowing this text painting device to saturate the fourpart musical texture for even greater effect.

Termini (1978; see also Engel, 1956, and Carter, 2001) explains that text painting is considered to be "a necessary ingredient of the style" (p. 4), so much so that any occurrence of this device has come to be known as a madrigalism regardless of the genre in which it appears. But not every historical example of text painting is as clear-cut as the one presented in Figure 1. How can the musicologist know for sure whether the composer of a madrigal intended for a particular collection of notes to illustrate the meaning of 
the sung words or whether those notes are simply a consequence of compositional decisions unrelated to the setting of the text?

The study described here took a statistical approach to this question by testing the appropriateness of three proposed definitions of text painting with regard to height-related imagery through a quantitative analysis of the madrigals of the sixteenth-century Italian composer Luca Marenzio.

\section{HYPOTHESES}

The purpose of this study was to discover whether the appearance of music conforming to any of the three definitions of height-related text painting proposed in the paragraph below, or combinations thereof, displayed a positive correlation with the presence of height-related imagery in the text accompanying that particular passage of music. For each of the definitions, the null hypothesis tested in the study therefore stated that no statistically significant difference would be obtained between the frequency with which music conforming to the definition was observed in association with height-related textual imagery and the frequency with which it was observed within the corpus of madrigals as a whole.

The definitions of height-related text painting that were tested in the study all found precedent in the excerpt from Wert's "Who will ascend to heaven" analyzed in the introduction. In general terms, the first definition required that the vocal part include a large leap, the second definition required that the vocal part include a scale-like passage of stepwise motion, and the third definition required that the vocal part move to the extremity of its pitch range. The procedures by which each of these definitions were then operationalized are explained in the Operational Definitions section below.

\section{METHOD}

Luca Marenzio was selected as the subject of this study because of the relative accessibility of the modern edition in which his music is now collected. Edited by J. Steele, this edition presents the music of each madrigal in score, accompanied by a non-musical setting of its text in which each poetic line occupies a separate printed line on the page. This format facilitated the researcher's ability both to isolate the lines of text in which height-related imagery appeared and to conduct a systematic sampling of the entire corpus, as described below.

The edition includes 29 of Marenzio's four-voice madrigals (1995), in addition to 1 eight-voice madrigal for double choir.[2] Of these works, the study excluded "Se 'l raggio de vostri occhi" because of its strophic construction - a compositional technique that largely precludes the possibility of text painting because all of the verses share the same musical setting. The edition also includes 169 of the composer's five-voice madrigals (1996), in addition to 3 eight-voice madrigals and 1 ten-voice madrigal for double choir. Of these works, the study excluded "Deh! dolce anima mia," which appears in Marenzio's Seventh Book of five-voice madrigals (1996, vol. 4), as it was composed by Antonio Bicci. The study therefore examined a corpus of 201 compositions representing 28 four-voice madrigals, 168 five-voice madrigals, 4 eight-voice madrigals, and 1 ten-voice madrigal. Marenzio also produced a number of six-voice madrigals (2001-2002), which were not included in this study.

\section{Procedure}

The lyrics of every madrigal in the corpus were first analyzed for references to height. The researcher identified not only references to upward and downward motion but also places and objects possessing a characteristic altitude such as celestial bodies, geographic features, and the imagined realms of heaven and hell. A complete index of the height-related words and phrases identified in the corpus appears in the Appendix. Given that some instances of textual imagery may arise from a single word while others may arise from a series of several words (i.e., from a phrase), the study examined the music associated with the entire poetic line in which the imagery appeared. This approach was taken in order to avoid both the difficulty of determining whether two adjacent height-related words constituted one instance of textual imagery or two-as could perhaps be debated with regard to the words "ascend" and "heaven" in the example from Figure 1-as well as the difficulty of ensuring that the systematically sampled passages to which the passages containing height-related imagery were to be compared would be equivalent in length and substance to the latter. 
With the set of poetic lines that contained references to height now in hand, the music associated with each of those lines was then analyzed to determine whether or not it conformed to any of the three operational definitions of text painting presented in the section below. The analysis was performed on the basis of individual vocal parts such that a single reference to height, when sung by every voice in a fivepart texture, was considered to offer five potential instances of text painting.[3] Adjacent repetitions of a poetic line in the music were counted as a single excerpt, while cases in which the repetition of a line was separated from its first iteration by other lines of text were counted as multiple excerpts. Cases in which a truncated poetic line appeared without its essential height-related word(s) were excluded from the analysis. The frequency with which these potential instances of text painting (the "Height-Related Excerpts") conformed to each of the operational definitions was then calculated.

In order to compare the music associated with height-related textual imagery to the music of the corpus as a whole, a systematic random sampling of the poetic lines in the corpus was first performed using a sampling interval of 13 lines. Each of the sampled lines may or may not have contained a reference to height. As with the set of poetic lines containing references to height described above, the music associated with each of these lines was then analyzed to determine whether or not it conformed to any of the three operational definitions of text painting given below. The musical analysis was again performed on the basis of individual vocal parts, and the frequency with which these excerpts (the "General Corpus Sample") conformed to the operational definitions was calculated as well.

Finally, for each definition or combination of definitions, the statistical significance of the difference between the observed frequencies in the two sets was assessed by applying the chi-square test for goodness of fit to the observed and expected frequencies of the definition in the general corpus sample. A significance threshold of $p \leq .05$ was used for all statistical tests, meaning that the probability of an observed difference being merely a result of chance (in accordance with the null hypothesis) would be no greater than one in twenty.

\section{Operational Definitions}

Three operational definitions of height-related text painting were tested in the study, each of which was formulated to account for the effect of a textual reference to height on the musical behavior of only the voice part in which that reference appeared. In other words, the definitions did not consider the effect of a reference appearing in one voice part on the musical behavior of the other voice parts nor on that of the whole ensemble - although in most cases, the references appeared in all parts simultaneously.

The first operational definition ("Definition A") required that the voice part incorporate a leap of at least five semitones (i.e., the interval of a perfect fourth) between one pitch and the next while singing the poetic line in which the reference to height was contained. In Figure 1, the voice leaps upward by seven semitones (a perfect fifth) from F4 to C5 while singing "Who will," the two words which begin the line in which the height-related reference appears. The definition imposed no restriction on the direction of the leap, meaning that for the purposes of this study, both upward and downward leaps fulfilled the definition regardless of whether the associated textual reference suggested upward or downward motion. The ambiguous directionality of this definition, and of the two that follow, allowed musical settings of both "high" and "low" textual references to be analyzed together as potential examples of height-related text painting as a combined phenomenon.

The second operational definition ("Definition B") required that the voice part incorporate unidirectional stepwise motion extending at least three whole or half steps while singing the poetic line in which the reference to height was contained. Pitches within the sequence were allowed to be re-articulated any number of times. In Figure 1, the voice rises from C5 to F5 in a sequence of two whole steps and one half step while singing the words "will ascend to heaven." The definition imposed no restriction on the direction of the stepwise motion, meaning that for the purposes of this study, both upward and downward sequences fulfilled the definition regardless of whether the associated textual reference suggested upward or downward motion.

Lastly, the third operational definition ("Definition C") required that the voice attain the highest or lowest pitch appearing anywhere within that vocal part while singing the poetic line in which the reference to height was contained. In Figure 1, the voice rises to an F5, which is the highest pitch found anywhere in the cantus part, while singing "heaven" in a mono-syllabic delivery that might be more accurately rendered as "heav'n." In keeping with the first and second operational definitions, above, this definition did not specify whether the textual reference should be accompanied by the highest pitch or the lowest pitch of the 
vocal range. For the purposes of this study, the appearance of either pitch therefore fulfilled the definition regardless of which one the associated textual reference suggested.

\section{RESULTS}

The corpus of madrigals examined in the study contained 2,241 lines of text. The analysis of these lines identified a wide range of height-related words and phrases, as shown in the Appendix. 228 lines of text (or roughly a tenth of those in the corpus) were found to include at least one such word or phrase. A total of 1,051 musical excerpts, each associated with one of the 228 height-related lines, were analyzed in the category of height-related excerpts.

A total of 803 musical excerpts, associated with 172 lines of text, were analyzed as part of the general corpus sample. 61 of these excerpts were associated with 14 lines of height-related text, while the rest of the excerpts in the general corpus sample were associated with lines of text not identified as containing references to height. Both the height-related excerpts and the excerpts from the general corpus sample were analyzed for the presence of music conforming to any of the three operational definitions described earlier. The results of this analysis are compiled in Table 1. The table is inclusive, meaning that excerpts reported as conforming to Definition A in line 1 may also agree with Definitions B and/or C, and so forth.

Table 1. Agreement of musical excerpts with operational definitions, inclusive.

\begin{tabular}{lcc}
\multicolumn{1}{c}{ Excerpts that conform to: } & $\begin{array}{l}\text { Height-Related } \\
\text { Excerpts }(N=1,051)\end{array}$ & $\begin{array}{l}\text { General Corpus } \\
\text { Sample }(n=803)\end{array}$ \\
\hline 1. Definition A & $857(81.54 \%)$ & $567(70.61 \%)$ \\
2. Definition B & $692(65.84 \%)$ & $442(55.04 \%)$ \\
3. Definition C & $539(51.28 \%)$ & $344(42.84 \%)$ \\
4. At least 1 Definition & $1,002(95.34 \%)$ & $708(88.17 \%)$ \\
& & \\
5. Definitions A and B & $558(53.09 \%)$ & $323(40.22 \%)$ \\
6. Definitions A and C & $489(46.53 \%)$ & $293(36.49 \%)$ \\
7. Definitions B and C & $381(36.25 \%)$ & $210(26.15 \%)$ \\
8. At least 2 Definitions & $744(70.79 \%)$ & $464(57.78 \%)$ \\
& & $181(22.54 \%)$
\end{tabular}

Given that $81.54 \%$ of the height-related excerpts were observed to conform to Definition A, 654.78 of the excerpts from the general corpus sample had also been expected to agree with the definition. As shown in line 1 of Table 1 , however, only 567 of the excerpts in the sample were observed to conform to that definition. The chi-square test for goodness of fit reveals this discrepancy to be significant, $\chi^{2}(1)=63.75$, $p<.001$, at the predetermined threshold of .05 . This means that the probability of the observed difference between the height-related excerpts and the general corpus sample occurring by chance is less than one in twenty (and in fact, at the reported $p$ value, less than one in a thousand), thereby refuting the null hypothesis associated with Definition A.

The chi-square test likewise produces significant results with regard to both Definition B and Definition C. Given that $65.84 \%$ of the height-related excerpts were observed to conform to Definition B, 528.71 of the excerpts in the general corpus sample had also been expected to agree with the definition. However, only 442 of those excerpts were observed to conform to the definition. This difference is also 
significant, $\chi^{2}(1)=41.63, p<.001$, thereby refuting the null hypothesis associated with Definition B. Similarly, given that $51.28 \%$ of the height-related excerpts were observed to conform to Definition C, 411.81 of the excerpts in the general corpus sample had also been expected to agree with the definition. However, only 344 of those excerpts were observed to conform to the definition. This discrepancy is again significant, $\chi^{2}(1)=22.92, p<.001$, thereby refuting the null hypothesis associated with Definition C. Additionally, the difference in the general corpus sample between expected and observed occurrences of at least one of the three definitions is significant as well, $\chi^{2}(1)=92.82, p<.001$.

The frequency with which various combinations of these definitions were observed in the excerpts also appears in Table 1. Because the table is inclusive, data reported in line 9 also appear in lines 1-8 and data reported in lines 5-8 also appear in lines $1-4$. For example, the 381 height-related excerpts reported in line 9 are also included amongst the 558 height-related excerpts reported in line 5, and those 558 excerpts are, in turn, included amongst the excerpts already reported in line 1 . The differences in the general corpus sample between expected and observed occurrences of both Definitions A and B, $\chi^{2}(1)=53.39, p<.001$, of both Definitions A and C, $\chi^{2}(1)=32.53, p<.001$, and of both Definitions B and C, $\chi^{2}(1)=35.44, p<.001$, are all significant. Furthermore, the difference in the general corpus sample between expected and observed occurrences of at least two of the three definitions is again significant, $\chi^{2}(1)=65.69, p<.001$. Lastly, the difference in the general corpus sample between expected and observed occurrences of all three definitions at once is also significant, $\chi^{2}(1)=36.58, p<.001$.

In addition to the results reported in Table 1, the frequencies with which the operational definitions appeared to the exclusion of other operational definitions within the height-related excerpts and the general corpus sample are shown in Table 2. In other words, unlike in Table 1, the data reported for each of the definitions listed here represent only those excerpts which do not conform to other definitions as well.

Table 2. Agreement of musical excerpts with operational definitions, exclusive.

\begin{tabular}{lcc}
\multicolumn{1}{c}{ Excerpts that conform ONLY to: } & $\begin{array}{l}\text { Height-Related } \\
\text { Excerpts }(N=1,051)\end{array}$ & $\begin{array}{l}\text { General Corpus } \\
\text { Sample }(n=803)\end{array}$ \\
\hline 1. Definition A & $152(14.46 \%)$ & $132(16.44 \%)$ \\
2. Definition B & $95(9.04 \%)$ & $90(11.21 \%)$ \\
3. Definition C & $11(1.05 \%)$ & $22(2.74 \%)$ \\
4. Any 1 Definition & $258(24.55 \%)$ & $244(30.39 \%)$ \\
5. Definitions A and B & & \\
6. Definitions A and C & $216(20.55 \%)$ & $142(17.68 \%)$ \\
7. Definitions B and C & $147(13.99 \%)$ & $29(3.61 \%)$ \\
8. Any 2 Definitions & $39(3.71 \%)$ & $283(35.24 \%)$ \\
& $402(38.25 \%)$ & $181(22.54 \%)$
\end{tabular}

As shown in line 1 of Table 2, $14.46 \%$ of the height-related excerpts conform only to Definition A. While 116.13 excerpts from the general corpus sample were therefore also expected to conform only to Definition A, 132 such excerpts were in fact observed. Using the chi-square test, this discrepancy is not significant, $\chi^{2}(1)=2.54, p=.11$, at the predetermined threshold of .05 . At a value of $p=.11$, the probability of the observed difference occurring by chance approaches one in nine. Consequently, this result must be interpreted as remaining consistent with a null hypothesis stating that Definition A will occur without the other definitions at an equal frequency in both the population of height-related excerpts and the general 
corpus sample. With regard to Definition B, however, the difference between expected and observed occurrences of the definition without the other two is indeed significant, $\chi^{2}(1)=4.60, p=.03$. At a value of $p=.03$, the probability of the observed difference occurring by chance is less than one in 33 , thereby refuting the associated null hypothesis. The difference between expected and observed occurrences of Definition $\mathrm{C}$ without the other definitions is likewise significant, $\chi^{2}=22.25, p<.001$. Furthermore, the difference between expected and observed occurrences of any one definition in the general corpus sample without either of the other two is also significant, $\chi^{2}=14.78, p<.001$.

The significance of the difference in the frequency with which combinations of two definitions appeared without the third definition, as reported in lines 5-8 of Table 2, was also tested. Whereas the difference in the general corpus sample between expected and observed occurrences of Definitions A and B without Definition $\mathrm{C}$ is significant, $\chi^{2}=4.05, p=.04$, the difference between expected and observed occurrences of Definitions A and C is not significant, $\chi^{2}<0.01, p=.97$, nor is the difference between expected and observed occurrences of Definitions B and C, $\chi^{2}=0.02, p=.88$. Furthermore, the difference in the general corpus sample between expected and observed occurrences of any two definitions without the third definition is also not significant, $\chi^{2}=3.07, p=.08$.

The final line of Table 2 is identical to the corresponding line in Table 1, and the difference between expected and observed occurrences of all three definitions in the general corpus sample has already been shown to be significant, $\chi^{2}(1)=36.58, p<.001$.

\section{DISCUSSION}

The results from Table 1 refute all three of the study's most basic null hypotheses, which stated that the frequency with which music conforming to Definition A, B, or C was observed in association with heightrelated textual references would equal the frequency with which it was observed throughout the entire corpus. Taken at face value, these results are therefore consistent with the three corresponding alternative hypotheses, which together predicted positive correlations between Marenzio's treatment of height-related textual imagery and his use of large leaps, stepwise motion, and extremes of pitch. That Marenzio would have employed such devices for the purpose of text painting hardly constitutes a departure in itself from the conventional historiography. For example, Engel (1956) establishes that the composer would often render concepts of movement and space, including height, by means of musical movement and space. Roche (1990) echoes this view. Bizzarini (2003) even attributes the success of Marenzio's musical style to his mastery of three key elements including imitazione delle parole - the "imitation of speech," or text painting.[4]

Although music conforming to all three of the definitions therefore appears significantly more often in conjunction with height-related textual references than in conjunction with an average line of text, these findings also reveal that some text painting techniques are more prevalent than others. The relatively low occurrence of Definition C, is consistent with Taruskin's (2010) assertion that for a madrigal composer, "musical tones all by themselves may not possess much in the way of semantic reference [...] but antithetical relationships between tones and tone-constructs can connote plenty" (p. 724). The large leaps described in Definition A provide just such an antithetical relationship, as do the stepwise passages described in Definition B. The extremes of pitch described in Definition C, while easily recognized on the page, may not be of such immediate significance to the listener-especially when concealed within an inner voice part. Even so, the relative infrequency of Definition C may also be a product of method: had the operational definition included not merely the highest and lowest pitches in a part's vocal range but instead any pitch within a certain proximity to those outer limits, a higher number of occurrences would almost certainly have been recorded.

Returning to the research question with which this study began, does the presence of music conforming to one of the three definitions tested above therefore indicate the presence of text painting when it accompanies a textual reference to height? Does the absence of such music, for that matter, indicate the absence of text painting? Given the correlations discussed above, it is tempting to infer that Marenzio's use of a large leap, stepwise motion, or an extreme of pitch to accompany a height-related line of text is, in and of itself, constitutive of text painting. In the case of Definition A, for example, the observation that Marenzio was more likely to incorporate a large leap when setting a height-related line suggests that any height-related excerpt in which he employs this compositional device must therefore constitute a bona fide instance of text painting. The logic of this reasoning is illustrated in Figure 2. 


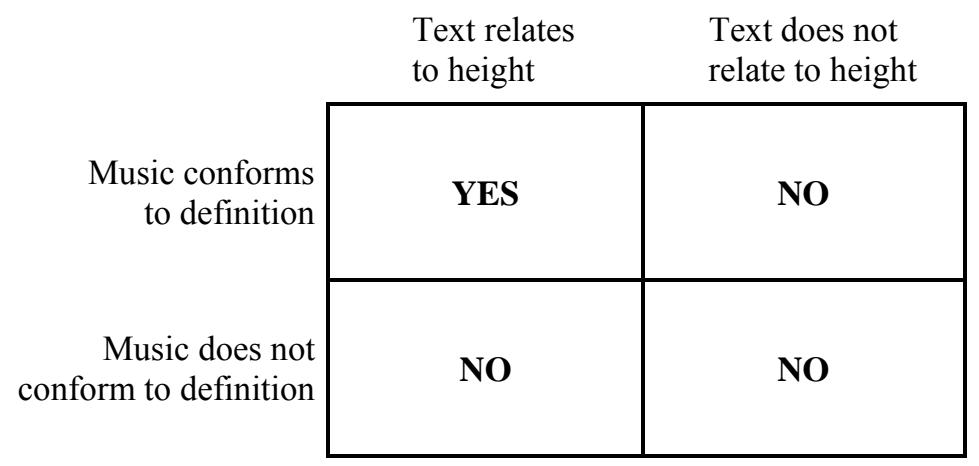

Fig. 2. Possible responses to the question, "Is this excerpt an example of height-related text painting?" if a correlated compositional device is assumed to be a constitutive compositional device.

Because all three of the definitions were found to be significant, the above argument is further encouraged by the observed positive correlation between the appearance of music conforming to any of the three definitions and the presence of height-related textual imagery. This again invites the assumption that the three compositional devices must be constitutive of height-related text painting when found in association with a textual reference to height. Of course, Figure 2 makes clear that excerpts in which the text does not contain a reference to height cannot be examples of height-related text painting regardless of whether or not the music conforms to one of the three definitions.

Taking into account the data presented in Table 2, however, our conclusions about the constitutive nature of the individual text-painting devices cannot stand. The table reveals that none of the definitions exhibited a positive correlation with the appearance of textual references to height when found in the absence of the other definitions. To begin with, the lack of a significant correlation in the results from line 1 of Table 2 suggests that the probability of an excerpt conforming exclusively to Definition A remains the same whether or not a reference to height appears in the text. Even more unexpected are the results from lines 2 and 3, which reveal negative correlations between the appearance of music conforming only to Definition B (line 2) or only to Definition C (line 3) and the presence of textual references to height.[5] The results shown in line 4 likewise reveal a negative correlation between the appearance of music conforming to just one of the three definitions and the presence of height-related imagery. On the whole, these results therefore suggest that the three text-painting devices are not by themselves constitutive of text painting. The negative correlations discovered are nevertheless consistent with the hypothesis that the musical devices are somehow related to the phenomenon of height-related text painting, but simply not in the manner proposed above.

Given that the presence of each text-painting device displays a positive correlation with the presence of textual references to height when measured on an inclusive basis but displays (in most cases) a negative correlation when measured on an exclusive basis, Marenzio's conception of height-related text painting must depend upon the use of multiple devices simultaneously. Consistent with this conclusion are the results from lines 5-8 of Table 1, which show significant positive correlations between the appearance of music conforming to combinations of at least two text-painting definitions and the presence of textual references to height. The results from line 5 of Table 2 likewise display a positive correlation between the appearance of music conforming exclusively to Definitions A and B and the presence of height-related imagery. These observations suggest that the probability of an excerpt conforming to both Definitions A and B, but not to Definition C, increases when a reference to height appears in the text, but they do not provide enough information to determine whether the probability of an excerpt conforming to Definitions $\mathrm{A}$ and $\mathrm{B}$ as well as to Definition $\mathrm{C}$ also increases with a reference to height.

Significant correlations were not observed, however, between the appearance of music conforming only to Definitions A and C or only to Definitions B and C and the presence of height-related imagery. A significant correlation was similarly absent between the appearance of music that satisfied only two of the three definitions and the presence of height-related imagery. Except for the combination of Definitions A and B, these results therefore suggest that Marenzio's simultaneous use of two text painting devices-like his use of the devices individually — is not by itself constitutive of text painting. 
The elimination of the three individual text-painting devices as well as (most) combinations of two devices suggests that all three devices are constitutive of height-related text painting when appearing together alongside a textual reference to height. After all, the results indicate a significant positive correlation between the appearance of music conforming to Definitions A, B, and C and the presence of height-related imagery. Must the three combined devices therefore constitute the essence of height-related text painting in the madrigal style? Not necessarily. There still exists the possibility that some other musical device has an equal or perhaps greater role to play in generating the phenomenon.

While gathering the data for this study, the researcher did observe elements of height-related text painting that were not encompassed by the three proposed definitions. The omission of the highest voice at a reference to "basso" in mm. 24-30 of Marenzio's (1996, vol. 3) "Che se 'l gridar," for example, appears to function as a form of text painting at the level of the ensemble instead of the individual voice part, as does the omission of the two lowest voices at a reference to "paradiso" in mm. 1-9 of his "Due rose, fresche" from the same collection. As shown in Table 3, a majority of the texted voice parts found in these examples also satisfy various combinations of the definitions examined in the study.[6] In short, the study can offer no evidence that the appearance of music conforming to Definitions $\mathrm{A}$, $\mathrm{B}$, and $\mathrm{C}$ would remain significant when measured on an exclusive basis without a fourth definition such as this.

Table 3. Excerpts associated with two height-related lines of text from the corpus demonstrate the presence of text painting not only within the individual voice parts but also as a function of ensemble voicing.

Line of Text

Voice Part

Un pianger basso, un mormorar occolto (mm. 24-30)

from "Che se 'l gridar" (Marenzio, 1996, vol. 3)

1. Canto (tacet)

2. Alto

3. Quinto

4. Tenore

5. Basso

Due rose fresch'e colte in paradiso (mm. 1-9)

from "Due rose, fresche" (Marenzio, 1996, vol. 3)

1. Canto

2. Quinto

3. Alto

4. Tenore (tacet)

5. Basso (tacet)
Conforms to Definition:

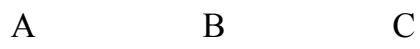

$\mathrm{C}$

$\begin{array}{ccc} & & \\ - & - & - \\ \text { No } & \text { No } & \text { No } \\ \text { No } & \text { Yes } & \text { No } \\ \text { Yes } & \text { Yes } & \text { Yes } \\ \text { Yes } & \text { Yes } & \text { Yes }\end{array}$

For similar reasons, no study of this kind can hope to account for all of the possible methods by which a madrigal composer as skilled as Marenzio could have chosen to illustrate a reference to height in the music. With regard to the essential nature of text painting, the most that the present study can hope to accomplish is to suggest that certain compositional devices and combinations of devices, though correlated with the appearance of height-related imagery, are not likely to constitute text painting in the absence of at least one additional compositional device. Such is the case for the devices described in all three of the individual definitions as well as for the combinations of Definitions A and C and Definitions B and C. 


\section{CONCLUSION}

The results of this study were consistent with the hypotheses that within the four- and five-voice madrigals of Luca Marenzio, there exist significant positive correlations between appearances of the three proposed definitions of text painting (i.e., the use of large leaps, stepwise motion, and extremes of pitch) and the presence of height-related imagery in the text. While Haar (2003) has argued that "Marenzio clearly had notions of decorum which led him to distinguish between superficial and more thoughtful matching of word and tone" (p. 11), the reported results would seem to point, as Haar does, to the conclusion that Marenzio operated well within the bounds of a style that that remains famous for its use of text painting.

Despite the correlations noted above, the results of the study were inconsistent with the idea that each of the three compositional devices can constitute an example of text painting by itself. Musical excerpts that did not satisfy all three of the proposed definitions displayed a positive correlation with the presence of height-related imagery only when they satisfied both the first and second definitions. The study did not eliminate the possibility that this combination of compositional devices, along with the combination of all three devices, may in fact constitute text painting without the necessary presence of some additional compositional device. The validity of other possible definitions of text painting, such as would encompass voicing strategies at the level of the ensemble, remains for future studies to explore, as does the validity of the definitions tested here with regard to the music of other madrigal composers.

In any event, it should be acknowledged that the search for a specific definition of text painting, or even several, may not be realistic to the psychological basis of the phenomenon itself. Owens (1999) seems wise to recognize that "while Marenzio's gestures seem quite obvious, it is not always easy to compile a 'definitive' catalogue - perhaps because the reader/listener, who constantly changes, is the other crucial component of the system" (p. 567). Without diminishing the importance of the conclusions reached above, this observation lays open yet another avenue of text-painting research in which the listener, not the music, becomes the object of empirical study.

\section{ACKNOWLEDGEMENTS}

I am indebted to Seth Coluzzi at Brandeis University for having introduced me to the beauty of Marenzio's madrigals, as well as to David Huron at the Ohio State University for having taught me how to analyze them in a quantitative manner. Additional thanks go to Lisa Zeidenberg at Brandeis University and to the staff of the Lewis Music Library at the Massachusetts Institute of Technology.

\section{NOTES}

[1] Correspondence may be addressed to Derek R. Strykowski, Department of Music, 220 Baird Hall, University at Buffalo, Buffalo NY 14260, U.S.A.

[2] This eight-voice madrigal, entitled "Donne, il celeste lume," also includes an optional ninth voice part associated with the second choir.

[3] The music identified in this step therefore represents not a sample set but rather the entire population of height-related musical excerpts to be found throughout the corpus.

[4] Bizzarini (2003) identifies the other two elements as counterpoint and the "nuova aria" style (p. 147).

[5] The results from line 1 of Table 2 also show a negative correlation, but not by a significant amount.

[6] Because the tacet voice parts did not include a height-related word or phrase, they were excluded from the data collected in the study (see Procedure). 


\section{REFERENCES}

Bizzarini, M. (2003). Luca Marenzio: The Career of a Musician Between the Renaissance and the CounterReformation. (J. Chater, Trans.). Burlington: Ashgate.

Carter, T. (2001). Word Painting. In Grove Music Online. Oxford: Oxford University Press. Retrieved from http://www.oxfordmusiconline.com

Engel, H (1956). Luca Marenzio. Florence: Olschki.

Haar, J. (2003). Marenzio After 400 Years. In I. Fenlon and F. Piperno (Eds.), Studi Marenziani (pp. 1-30). Venice: Edizioni Fondazione Levi.

Marenzio, L. (1995). The complete four voice madrigals: for mixed voices. (J. Steele Ed.). New York: Gaudia Music and Arts.

Marenzio, L. (1996). The complete five voice madrigals: for mixed voices. (J. Steele Ed.). New York: Gaudia Music and Arts.

Marenzio, L. (2001-2002). The complete six voice madrigals: for mixed voices. (J. Steele and S. Court, Eds.). New York: Gaudia Music and Arts.

Owens, J. A. (1999). Marenzio and Wert Read Tasso: A Study in Contrasting Aesthetics. Early Music, 27(4), 555-74. https://doi.org/10.1093/earlyj/XXVII.4.555

Roche, J. (1990). The Madrigal (2nd ed.). Oxford: Oxford University Press.

Taruskin, R. (2010). Music from the Earliest Notations to the Sixteenth Century. The Oxford History of Western Music (vol. 1). Oxford: Oxford University Press.

Termini, O. (1978). The Transformation of Madrigalisms in Venetian Operas of the later Seventeenth Century. The Music Review 39(1), 4-21.

Wert, G. de (1588). Who will ascend to heaven. In N. Yonge (Ed.), Musica Transalpina (no. 11). London: Thomas East. 


\section{APPENDIX}

The following Italian words and phrases were identified as conveyors of height-related imagery within the corpus of madrigals examined in the study. Some words and phrases were identified in multiple locations. Note that the parenthetical translations given below are those provided in the edition itself, for which reason their English conjugation is not always accurate outside the context of the poetry.

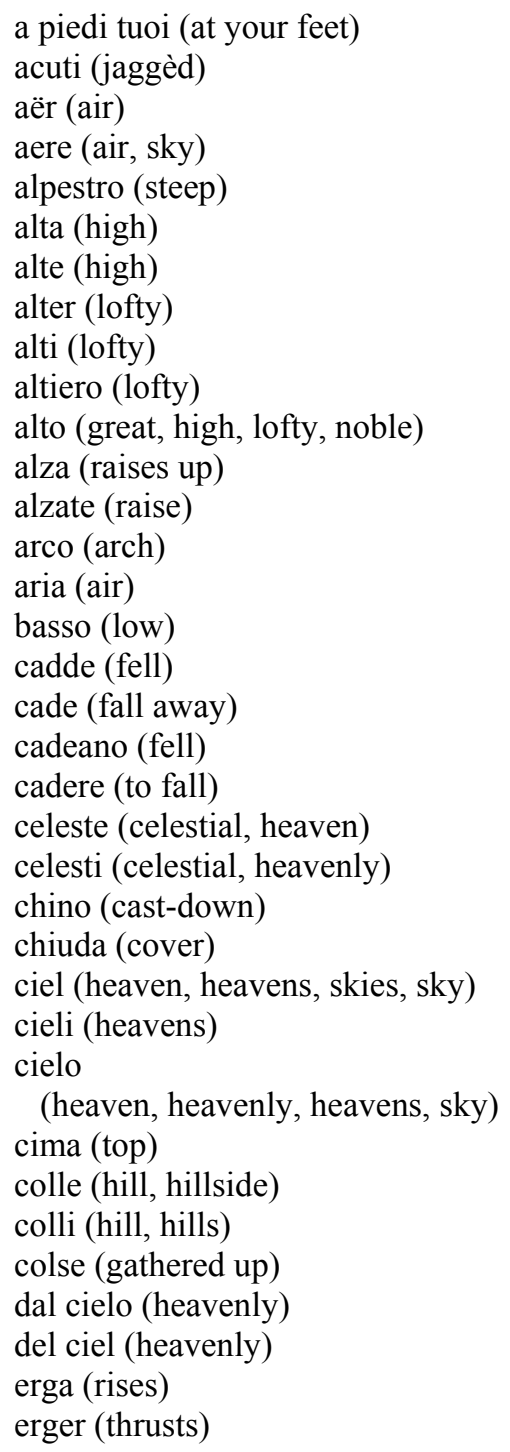

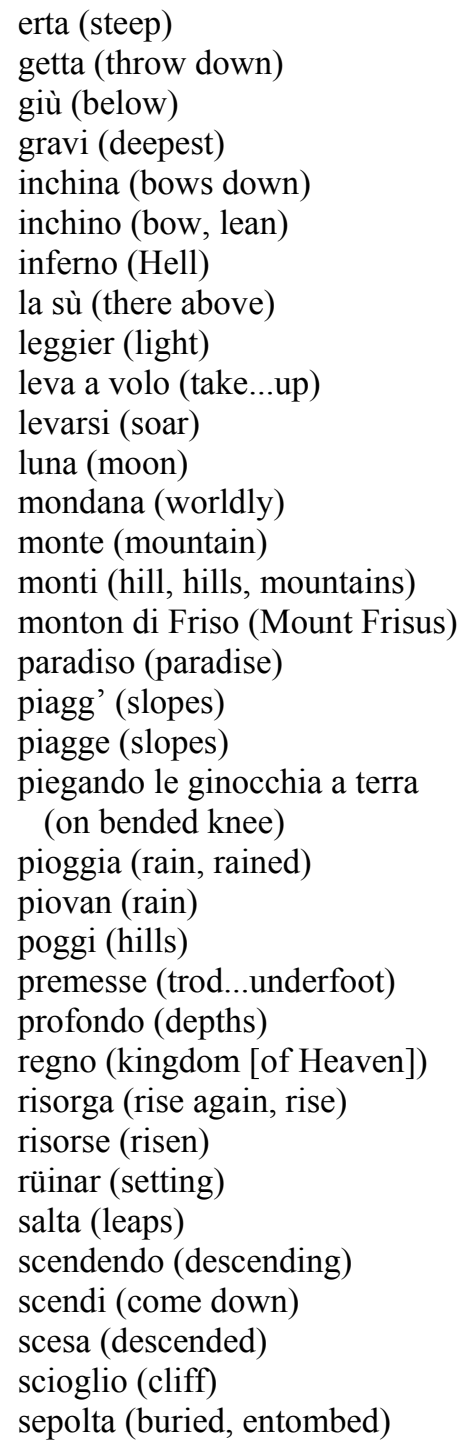

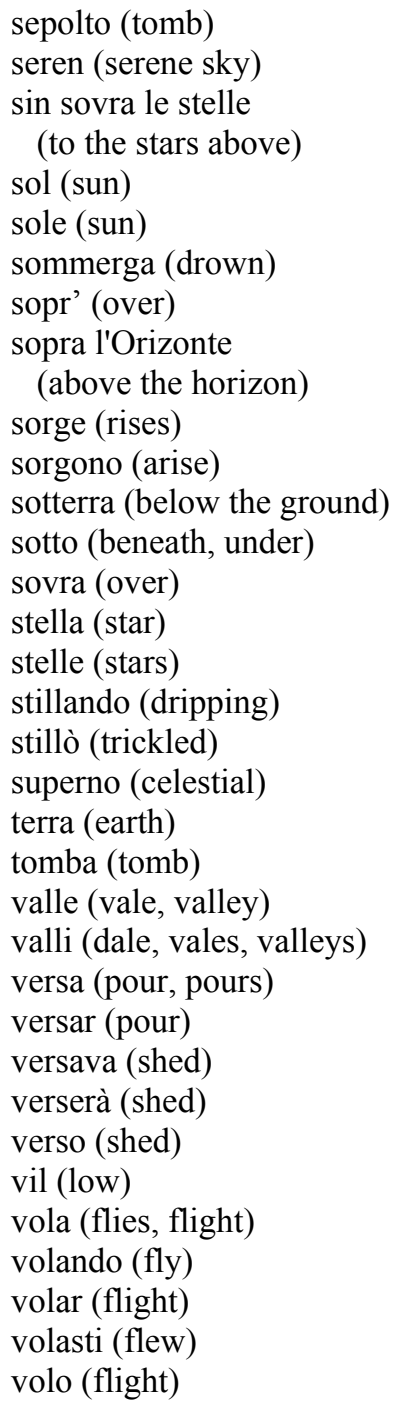

